University of Nebraska - Lincoln

DigitalCommons@University of Nebraska - Lincoln

USDA National Wildlife Research Center - Staff Publications
U.S. Department of Agriculture: Animal and Plant Health Inspection Service

2019

\title{
Parasitism, host behavior, and invasive species
}

Sarah N. Bevins

National Wildlife Research Center,

Follow this and additional works at: https://digitalcommons.unl.edu/icwdm_usdanwrc

Part of the Life Sciences Commons

Bevins, Sarah N., "Parasitism, host behavior, and invasive species" (2019). USDA National Wildlife Research Center - Staff Publications. 2236.

https://digitalcommons.unl.edu/icwdm_usdanwrc/2236

This Article is brought to you for free and open access by the U.S. Department of Agriculture: Animal and Plant Health Inspection Service at DigitalCommons@University of Nebraska - Lincoln. It has been accepted for inclusion in USDA National Wildlife Research Center - Staff Publications by an authorized administrator of DigitalCommons@University of Nebraska - Lincoln. 
Bevins, S.N. 2019. Parasitism, host behavior, and invasive species. pgs 273-278. In: J.C. Choe, editor. Encyclopedia of Animal Behavior, 2nd edition, vol 1. Elsevier, Academic Press. 3048 pp.

\section{Title}

Parasitism, host behavior, and invasive species

\section{Author}

Sarah N Bevins, National Wildlife Research Center, Fort Collins, CO, United States

\section{Keywords}

Disease;

Enemy release;

Infection;

Invasion;

Non-native;

Parasite-altered behavior;

Parasite manipulation;

Apparent competition;

Conservation

\section{Introduction}

Animal behavior and parasitism are inextricable linked. In many cases, host behavior can affect what parasites are encountered. In other cases, parasites can manipulate the behavior of the host in an attempt to maximize their own transmission. These long-standing interactions are now further complicated by species movement around the globe. The list of introduced species that have become invasive includes parasites that have adapted to new hosts in areas of introduction, as well as invasive hosts that alter the association between existing parasite-host assemblages. Researchers have documented differences in rates of parasitism and in the consequences of parasite infection between invasive and native hosts, and sometimes these differences are a result of behavioral differences, either pre-existing host behaviors or host behaviors that are altered as a consequence of infection. Parasites have been shown to mediate interactions between native and invasive hosts; occasionally, these parasites determine the outcome of invasions. The effects on native species can be severe, and to that end, interactions between invasive species, parasites, and behavior have ramifications for conservation biology.

\section{Parasite-Altered Behaviors and Invasion}


Seminal research by Park (1948) demonstrated how a parasite can effect population dynamics and interactions between species. Over a period of 4 years, 211 populations of flour beetles were maintained in a laboratory. These populations consisted of two species, Tribolium confusum and $T$. castaneum, which were either kept alone or in mixed-species colonies. Mixed-species colonies displayed marked competitive interactions, with one species always going extinct during the experiment. Park also added a naturally occurring protozoan parasite (Adelina tribolii) to some mixed-species populations and the results were striking: $T$. castaneum often went extinct when the parasite was present, but $T$. confusum died out when the parasite was absent (Park, 1948). These were the first results to demonstrate the existence of parasite-mediated competition. It has now been well-established that parasites have the ability to regulate host populations, thus influencing both the structure of biological communities and the outcome of species invasions (Moore, 2002).

For instance, the thorny-headed acanthocephalan parasite, Pomphorhynchus laevis (the literal translation of the genus name is blister-snout, referring to the bulb-like front end, which is covered with spiny projections) lives in freshwater environments and the larval forms infect small aquatic crustaceans called amphipods. These infected amphipods must then be consumed by a fish in order for the adult form of the parasite to mature. Amphipods infected with the acanthocephalan parasite exhibit behaviors that differ from their uninfected counterparts. For example, infected amphipods will often move toward light (positive phototaxis) - or at least will not shy away from it like uninfected individuals - and this increases the chance that they will be preyed upon by fish. Other altered behaviors in P. laevis-infected amphipods include changes in antipredator behavior and more conspicuous coloration. These changes have been shown to increase the transmission of the parasite to its final host, but represents the ultimate cost for the amphipod.

Research like this, on amphipods and their parasites, has produced a wealth of information on how parasites can manipulate the behavior of their hosts (Bethel \& Holmes, 1973, 1977). Bethel and Holmes $(1973,1977)$, were the first to clearly demonstrate that amphipods infected with certain acanthocephalan parasites moved towards light, rather than away from it. More recent work has taken this one step further and has used amphipods to better understand the role parasites play in species invasions. Parasites can influence species invasions through a variety of mechanisms. The simplest is a parasite that establishes in a new area or in a new host. Another way parasites play a role in species invasions is an invasive species that establishes in new areas but does not bring all of the parasites that affect it in its native range. This release (an example of the enemy release hypothesis) leads to rapid increase and distribution of the invasive host species. Alternatively, an invasive species can bring parasites with it from its native range and these parasites may then be able to infect native hosts. The final way a parasite can play a role in species invasions in when an invasive species becomes an alternative host for native parasites. This can result in spillback or dilution. Recent work has demonstrated all of these situations and research on amphipod systems in particular has examined how parasite-modified behaviors influence the outcomes of species invasions (Dunn \& Hatcher, 2015; Dunn et al., 2012). 


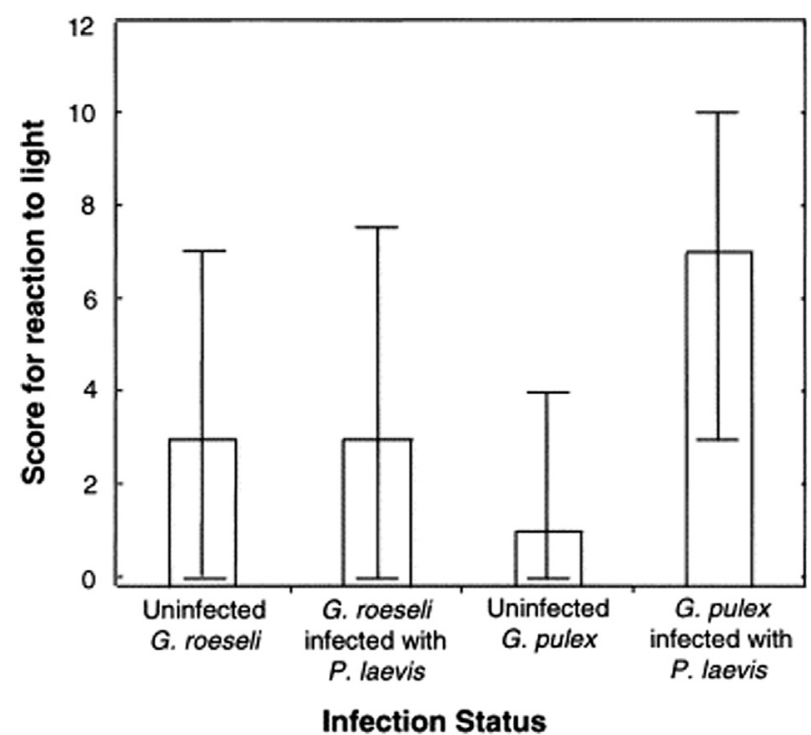

Figure 1

In France, Bauer et al. (2000) examined a non-native amphipod (Gammarus roeseli) that has invaded freshwater habitats already supporting a native amphipod (G. pulex). These native amphipods exhibit classic behavioral alterations when infected with a native acanthocephalan parasite, but the new invasive amphipod does not (Bauer, Trouve, Gregoire, Bollache, \& Cezilly, 2000). The parasite was found in both species of amphipods, but only the native amphipod species had an altered response to light when infected with the parasite (Figure 1). This suggests that when infected, the native amphipod species is under more intense predation pressure than the invasive species. Unequal predation pressure could ultimately aid benefit the invasive species by allowing it to establish more easily.

This system in an example of a parasite influencing the interactions between a native and an invasive species by altering host behavior, and there are many other documented examples that fall into this category. In another amphipod example, MacNeil et al. found a species of native amphipod that hosted a microsporidian parasite. This made the native more likely to be preyed upon by a larger, invasive amphipod that is resistant to infection (MacNeil, Dick, et al., 2003; MacNeil, Fielding, et al., 2003). In addition, Georgiev and others examined native Mediterranean brine shrimp that are hosts to cestode parasites which alter coloration, as well as behaviors including positive phototaxis, increased swimming time, and augmented surfacing behavior; all of these are behaviors that potentially increase the chances of cestode transmission to its final avian host (Georgiev, Sanchez, Vasileva, Nikolov, \& Green, 2007). These parasites are not found in a new, rapidly invading brine shrimp species. Calvo-Ugarteburu and McQuaid (1998) found that a mussel species native to South Africa (Perna perna) hosts two trematode parasites, one that alters behaviors and thereby reduces growth and one that castrates the host. A new invasive mussel (Mytilus galloprovincialis) is not infected by either parasite (Calvo-Ugarteburu \& McQuaid, 1998). This sets up a situation similar to the previously described acanthocephalan/amphipod system, whereby parasites reduce the fitness of the native species, but not the invasive. 
Another examples involves the amphipod, Gammarus roeseli, and an acanthocephalan parasite (Polymorphus minutus). Research revealed that both infected and uninfected G. roseli remained benthic, presumably away from the surface of water, where they would be subject to high predation pressure from the acanthocephalan's final avian host (Medoc, Bollache, \& Belsel, 2006). Another amphipod species (Dikerogammarus villosus) recently invaded the same area where $P$. minutus is found, but the invasive amphipod is larger and can prey upon smaller crustaceans, like G. roeseli. Laboratory experiments revealed that when there is no predatory amphipod around, both infected and uninfected G. roeseli spend a majority of their time at the bottom of the water column, but the addition of the predatory, invasive amphipod resulted in infected amphipods (not their uninfected conspecifics) dispersing to surface areas of a water column. This precise behavioral manipulation would allow the parasite to avoid predation by an unsuitable final host - an invasive predatory amphipod - while exposing its current host to predation by the appropriate final host. This offers a unique example of highly specific parasite-modified behaviors. Later research (Jacquin, Mori, Pause, Steffen, \& Medoc, 2014), however, suggests that this example doesn't hold up. Additional experiments revealed that there was no difference in infected amphipod behavior when exposed to an avian predator (the parasite's final host) or to a fish predator. There was also no evidence to suggest that the behavior of infected amphipods led to an increase in parasite transmission to its final avian host.

This final point is key to understanding parasite-modified behaviors. Organisms infected with a pathogen or parasite often behave differently, even in the absence of parasite control. For example, having a fever when infected by a pathogen often results in lethargy and that lethargy would manifest as decreased activity levels. Many of these behavioral differences are simply byproducts of infection and are not necessarily an adaptive manipulation on the part of the parasite to increase transmission (i.e. fitness). In order to demonstrate that altered behaviors are true manipulations, the parasite must benefit from the changed behaviors. The inability to demonstrate an increase in transmission to the final host in the above example (Jacquin et al., 2014; Medoc et al., 2006) suggests that the behaviors they were documenting did not lead to increase in parasite fitness. While the presence of the parasite appeared to generate altered behaviors, more data are needed to determine if or how altered behaviors increase the transmission of the parasite to its final host.

Rabies is another disease where infected hosts behave differently than uninfected conpecifics and it has also invaded many areas around the world. Rabies records data back several hundred years in some parts of Africa, but its appearance in sub-Saharan Africa is thought to be relatively recent, suggesting an introduction with domestic dogs in the late 1800s. The impact on wildlife, especially native carnivores, has been severe. Rabies has led to the local extinction of African wild dogs from Serengeti National Park, and Ethiopian wolves - a species with fewer than 600 individuals remaining - lose up to $70 \%$ of pack members during rabies outbreaks. Rabies has been documented in many other native African species as well, but domestic dogs are believed to be the primary reservoir. 
While rabies is associated with some of the most dramatic examples of altered behaviors, it is difficult to establish if these behaviors are byproducts of infection or if they are deliberate manipulations by the virus to increase transmission opportunities. The rabies virus is transmitted by infectious saliva, although it initially infects the peripheral nervous system of the host. Movement of the virus from the peripheral to the central nervous system is accompanied by a suite of behavioral changes, including increased aggression and biting behavior, as well as an abundance of saliva, the result of an impaired swallowing reflex. All of these behaviors would appear to offer increased transmission opportunities for the virus, but it should be noted that not all organisms demonstrate aggressive behaviors when infected with rabies. Bats for instance can be infected by conspecifics in highly aggregated bat roosts where the virus can aerosolize. Aerosolization would offer the virus an alternative transmission route that would potentially circumvent the need for transmission via aggressive host encounters. Recent suggestions (Hueffer et al., 2017) that behaviors resulting from rabies infection are an example of parasitemodification would need to demonstrate increased fitness on the part of the virus in order to be convincing. It's possible that host behavior may offer enough transmission opportunities even in the absence of parasite-modified behavior and this would result in relatively weak selection pressure for manipulation.

This list of parasite-modified behaviors influencing invasions continues to grow as researchers delve deeper into species interactions. Invasions facilitated by parasites are relatively rare compared to the sheer number of invasions not known to be facilitated by parasites; however, these examples illustrate that parasite-modified behaviors can influence the invasion process and profoundly contribute to community structure, species establishment, and species extinction.

\section{Host behavior and parasite encounters}

While parasite-modified host behavior has received a lot of attention, the vast majority of research on behavior and parasites involves host behavior that is not controlled by an infectious agent. Host behavior in general has a profound effect on how, when, and if hosts encounter parasites in the environment and those encounters are increasingly in flux because of species introductions and invasions. The introduction of a novel species can 'enhance' an existing parasite-host relationship, as was the case with Erythroneura variablis, a nonnative leafhopper insect that invaded California in 1980. The region's native leafhopper was parasitized by Anagrus epos, a wasp parasitoid that infected leafhopper eggs. The egg-laying behavior of the native grape leaf-hopper made it more prone to parasitism by the parasitoid when compared with the invasive species (Settle \& Wilson, 1990). 
The leafhopper had presumably existed with the parasitoid before the arrival of a nonnative leafhopper. After that introduction, however, the native leafhopper's population declined precipitously, because the large, combined leafhopper population provided by the invasive species allowed the parasitoid numbers to increase drastically, which in turn intensified parasitism pressure on the native species. This is known as apparent competition, in which it appears that one species' decline is due to the arrival of a new species, when in fact that decline is linked to a shared parasite or predator (Hudson \& Greenman, 1998). All of these indirect effects are based on the native leafhopper's egg-laying behavior, which make it more prone to parasitization than the invasive leafhopper. In this case, it is the intrinsic host behavior that when combined with parasitism gives the invasive species an advantage over its potential competitor. Settle and Wilson (1990) claimed a two-part advantage for the invasive leafhopper: (1) the parasitoid lowered native leaf-hopper population numbers allowing the invasive to establish and (2) the native suffered from an increased parasitoid population brought about by greater overall host numbers, as it was a multi- host pathogen. This was one of the first documented instances of the indirect effects that parasites can have during an invasion. The decline of species because of invasive parasites, or invasive hosts that alter existing parasite/host systems, has contributed to this, and other, conservation problems.

The Hawaiian archipelago, for instance, was home to a vast number of endemic avifauna, but no mosquitoes. Culex quienquefasciatus, the southern house mosquito, arrived with European sailors in 1826. The 1900s saw potentially hundreds of nonnative bird species purposely released in Hawaii, and some likely harbored avian malaria and avian pox (Figure 2). Migratory birds probably carried the parasites to the islands before human settlers arrived; however, there was no mosquito vector to transmit the malarial parasite. In addition, the parasite prevalence in migratory birds was most likely low since migration to Hawaii, either purposeful or accidental, is a long, arduous journey from even the closest landmass. Only relatively healthy birds with good body condition, and by extension, a low parasite load, would survive migration. The combination of introduced parasites, introduced vectors, and long-isolated avian populations lacking evolutionary experience with these pathogens proved catastrophic. More than 50\% of Hawaii's endemic birds are now extinct (Warner, 1968). 


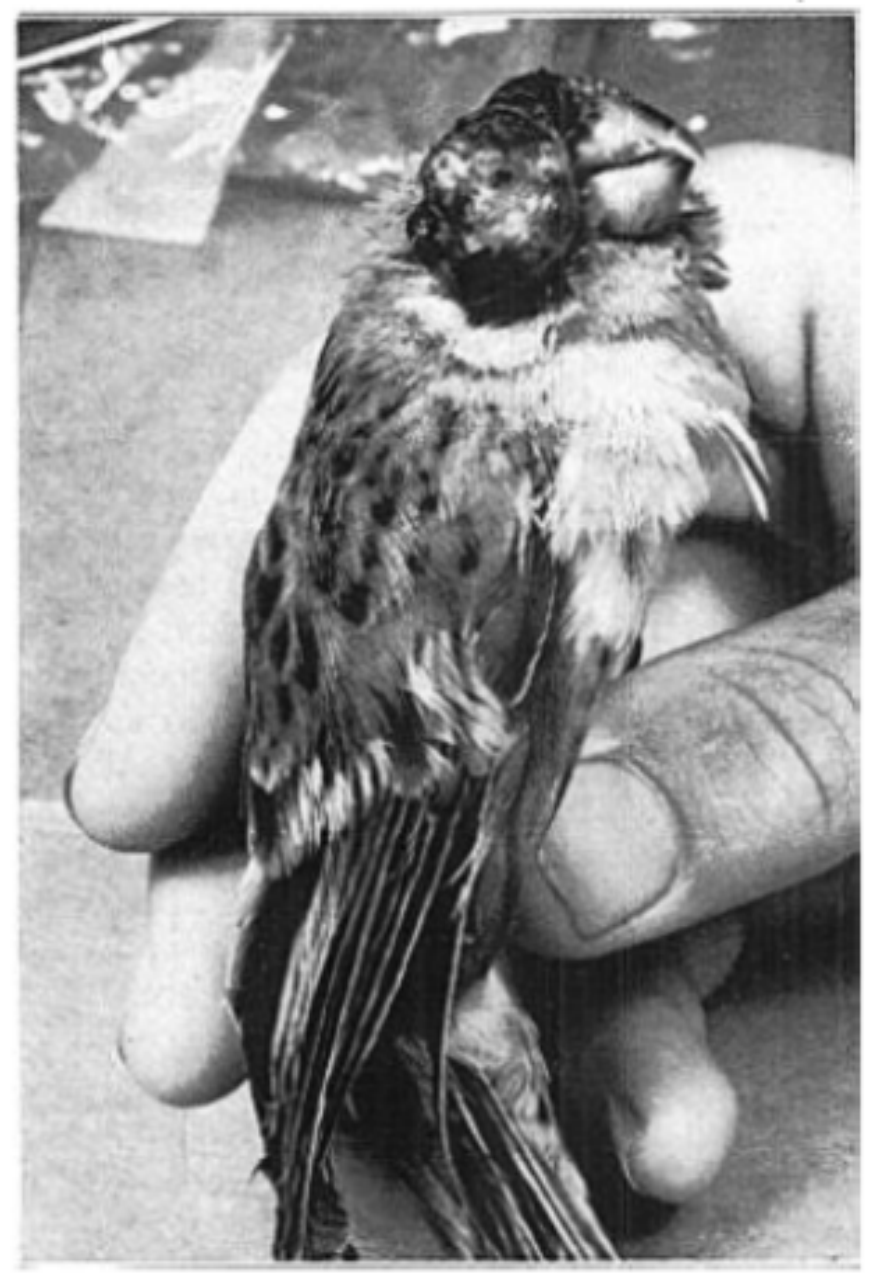

Figure 2

The survival of some remaining species, however, may be attributable to altered behaviors. In the 1960s, Warner (1968) observed nonnative birds in Hawaii sleeping with their face and bill tucked in, and their legs pulled up into their feathers, while native Hawaiian birds slept with their faces and legs exposed. These behaviors left the native birds exposed to mosquito bites, and to the malaria parasite the mosquitoes carry, throughout the night; however, observations made by van Riper and colleagues many years later found native birds sleeping with exposed areas tucked in. Presumably, the sleeping behaviors changed in response to the strong selection pressures exerted from parasites transmitted by mosquito bite (van Riper, van Riper, Goff, \& Laird, 1986). Daily altitudinal migrations also appear to have shifted, allowing some bird species to avoid peak mosquito biting times by periodically moving to higher altitudes that are mosquito-free.

The bacteria that causes bovine brucellosis is another introduced pathogen that has clear examples of how host behavior influences contact rates and transmission opportunities. Brucella abortus was likely 
introduced to North America with European cattle imports (Jack C. Rhyan et al., 2013; J. C. Rhyan \& Spraker, 2010), but it can infect elk (Cervus canadensis) and bison (Bison bison). It can cause a variety of clinical symptoms, including abortion in infected females. Contact with aborted fetuses or afterbirth is one of the primary routes of transmission both within and between species. Bison populations in this region tend to have higher $B$. abortus prevalence (40-60\%) than elk (2-3\%) (Kamath et al., 2016) and one reason may be birthing behavior. Bison females often birth in or near their herd and that increases the likelihood of other herd members contacting infected afterbirth. Elk, in contrast, give birth alone and meticulously clean afterbirth from the site to prevent predators from finding their offspring, which remain concealed for several days. These behaviors lower the probability of $B$. abortus transmission to other elk or to other susceptible species, such as bison and cattle (Cheville, McCullough, Paulson, \& Council, 1998).

Despite the higher prevalence in bison, most $B$. abortus transmission to cattle appears to come from elk. This can once again be linked to behavior. More specifically, to behavior in conjunction with population density. There is only one area of the US where B. abortus persists in cattle and this area also includes elk feeding grounds, where elk populations receive supplemental food in the winter. Feed grounds were established to prevent large-scale die-offs during severe winters, but the artificially high concentration of animals in one area is the perfect setting for disease transmission. The timing of abortion in Brucellainfected elk coincides with feed ground congregation, and, correspondingly, elk associated with feed grounds have higher Brucella seroporevalence (10-30\%). Elk behavior also includes large migratory movements which can bring them into contact with cattle more often than bison.

Rinderpest is another accidently introduced virus, in this case, to Africa, and it devastated native ungulate populations. In, 'The Rise of our East African Empire,' Frederick John Dealtry Legard wrote, 'never before in the memory of man, or by the voice of tradition, have the cattle died in such numbers; never before has the wild game suffered.' The grouping behavior present in many large herds of African ungulates offered an easy target for a pathogen that is rapidly and directly transmitted in dense groups. In fact, it has been suggested that, historically, the Sahara had acted as a natural barrier that prevented the pathogen from crossing into Africa from Europe and the Middle East because it does not support high ungulate densities. Group sizes are often larger in open habitats with more optimal forage, like those seen in some areas of Sub-Saharan Africa. While grouping behavior may reduce encounters with predators, is was often assumed that those benefits would come with the cost of increased transmission of diseases among the group. A recent meta-analysis did find a positive association between group size and parasitism, although the effect was not particularly strong (Rifkin, Nunn, \& Garamszegi, 2012), leaving some of these assumptions open to debate.

Wildlife populations eventually rebounded from rinderpest after a massive campaign to vaccinate cattle, which were the main reservoir host. These rebounds showed just how profound the effects of this virus 
were (Bengis, Kock, \& Fischer, 2002). Wildebeest and other ungulate populations increased up to sevenfold, followed by a dramatic increase in predator numbers as well. Such dramatic population changes had ecosystem-level effects. Non-ungulate grazers such as zebra had to compete for forage. Fire-cycles were altered because foraging pressure changed the type and amount of plant material available. The last case of rinderpest was documented in 2011 and it was officially eradicated later that year. This makes it only the second disease in history, after smallpox, to be eradicated on a global scale.

\section{Future Questions}

Our understanding of the role animal behavior plays in parasite-mediated invasions is incomplete and many questions remain. While many hypotheses have been suggested to explain invasion processes, it is often hard to disentangle the mechanisms driving an invasion. Is it a case of enemy release, or apparent competition? Is the invasive species in question simply a more aggressive competitor? Has it tapped into a previously limiting resource? Answering these questions is further complicated by invasion being a many faceted process, involving colonization, establishment, and spread. Behavior and/or parasitism may play a role only in one part of an invasion.

Experimental manipulation and long-term studies are required if we are to decode the contribution that parasites and host behavior have on species invasions. Demonstrating that host behavior is a result of parasite-modification requires a documented increase in parasite fitness, otherwise the effects on the host could just be a side effect of pathology. Long-term studies are also needed to determine whether and how parasites evolve to infect new invasive hosts, or vice-versa. Invasive hosts may eventually pick up new parasites, but on what time scale, and what happens to those new associations over time? It follows that there are many questions remaining about how parasites and the behavior of their hosts influence population dynamics and community structure in the context of species invasions. 


\section{Further Reading}

Bauer, A., Trouve, S., Gregoire, A., Bollache, L., \& Cezilly, F. (2000). Differential influence of Pomphorhynchus laevis (Acanthocephala) on the behaviour of native and invader gammarid species. International Journal for Parasitology, 30(14), 1453-1457.

Bengis, R. G., Kock, R. A., \& Fischer, J. (2002). Infectious animal diseases: the wildlife/livestock interface. Revue Scientifique et Technique - Office International des Épizooties, 21(1), 53-65.

Bethel, W. M., \& Holmes, J. C. (1973). Altered evasive behavior and responses to light in amphipods harboring acanthocephalan cystacanths. The Journal of Parasitology, 945-956.

Bethel, W. M., \& Holmes, J. C. (1977). Increased vulnerability of amphipods to predation owing to altered behavior induced by larval acanthocephalans. Canadian Journal of Zoology, 55(1), 110115.

Calvo-Ugarteburu, G., \& McQuaid, C. D. (1998). Parasitism and invasive species: effects of digenetic trematodes on mussels. Journal of Experimental Marine Biology and Ecology, 169, 149-163.

Cheville, N. F., McCullough, D. R., Paulson, L. R., \& Council, N. R. (1998). Brucellosis in the greater Yellowstone area: National Academies Press.

Dunn, A. M., \& Hatcher, M. J. (2015). Parasites and biological invasions: parallels, interactions, and control. Trends in Parasitology, 31(5), 189-199. doi:http://dx.doi.org/10.1016/j.pt.2014.12.003

Dunn, A. M., Torchin, M. E., Hatcher, M. J., Kotanen, P. M., Blumenthal, D. M., Byers, J. E., . . . Perkins, S. E. (2012). Indirect effects of parasites in invasions. Functional Ecology, 26(6), 1262-1274. doi:10.1111/j.1365-2435.2012.02041.x

Georgiev, B. B., Sanchez, M. I., Vasileva, G. P., Nikolov, P. N., \& Green, A. J. (2007). Cestode parasitism in invasive and native brine shrimps (Artemia spp.) as a possible factor promoting the rapid invasion of $A$. franciscana in the Mediterranean region. Parasitology Research, 101(6), 16471655.

Hudson, P., \& Greenman, J. (1998). Competition mediated by parasites: biological and theoretical progress. Trends in Ecology and Evolution, 13(10), 387-390.

Hueffer, K., Khatri, S., Rideout, S., Harris, M. B., Papke, R. L., Stokes, C., \& Schulte, M. K. (2017). Rabies virus modifies host behaviour through a snake-toxin like region of its glycoprotein that inhibits neurotransmitter receptors in the CNS. Scientific reports, 7(1), 12818. doi:10.1038/s41598-01712726-4

Jacquin, L., Mori, Q., Pause, M., Steffen, M., \& Medoc, V. (2014). Non-specific manipulation of gammarid behaviour by $P$. minutus parasite enhances their predation by definitive bird hosts. PLOS ONE, 9(7), e101684. doi:10.1371/journal.pone.0101684

Kamath, P. L., Foster, J. T., Drees, K. P., Luikart, G., Quance, C., Anderson, N. J., . . Cross, P. C. (2016). Genomics reveals historic and contemporary transmission dynamics of a bacterial disease among wildlife and livestock. Nature Communications, 7, 11448. doi:10.1038/ncomms11448 https://www.nature.com/articles/ncomms11448\#supplementary-information

MacNeil, C., Dick, J. T. A., Hatcher, M. J., Terry, R. S., Smith, J. E., \& Dunn, A. M. (2003). Parasitemediated predation between native and invasive amphipods. Proceedings of the Royal Society $B$, 270(1521), 1309-1314.

MacNeil, C., Fielding, N. J., Dick, J. T. A., Briffa, M., Prenter, J., Hatcher, M. J., \& Dunn, A. M. (2003). An acanthocephalan parasite mediates intraguild predation between invasive and native freshwater amphipods (Crustacea). Freshwater Biology, 48(12), 2085-2093. 
Medoc, V., Bollache, L., \& Belsel, J. N. (2006). Host manipulation of a freshwater crustacean (Gammarus roeseli) by an acanthocephalan parasite (Polymorphus minutus) in a biological invasion context. International Journal for Parasitology, 36(13), 1351-1358.

Moore, J. (2002). Parasites and the behavior of animals. Oxford: Oxford University Press.

Park, T. (1948). Interspecies competition in populations of Trilobium confusum Duval and Trilobium castaneum Herbst. Ecological Monographs, 18(2), 265-307. doi:10.2307/1948641

Rhyan, J. C., Nol, P., Quance, C., Gertonson, A., Belfrage, J., Harris, L., . . Robbe-Austerman, S. (2013). Transmission of Brucellosis from elk to cattle and bison, Greater Yellowstone Area, USA, 20022012. Emerging Infectious Diseases, 19(12), 1992-1995. doi:10.3201/eid1912.130167

Rhyan, J. C., \& Spraker, T. R. (2010). Emergence of diseases from wildlife reservoirs. Veterinary Pathology Online, 47(1), 34-39.

Rifkin, J. L., Nunn, C. L., \& Garamszegi, L. Z. (2012). Do animals living in larger groups experience greater parasitism? A meta-analysis. The American Naturalist, 180(1), 70-82. doi:10.1086/666081

Settle, W. H., \& Wilson, L. T. (1990). Invasion by the variegated leafhopper and biotic interactions parasitism, competition, and apparent competition. Ecology, 71(4), 1461-1470.

van Riper, C., van Riper, S. G., Goff, M. L., \& Laird, M. (1986). The Epizootiology and Ecological Significance of Malaria in Hawaiian Land Birds. Ecological Monographs, 56(4), 327-344. doi:10.2307/1942550

Warner, R. E. (1968). The role of introduced diseases in the extinction of the endemic Hawaiian avifauna. The Condor, 70(2), 101-120.

\section{Figure Legend}

Figure 1: Median values for reaction to light according to infection status. Scores range from 0 (strongly photophobic) to 10 (highly photophilic). A score of 5 indicates no preference in relation to light. Bars show the interquartile range. From Bauer et al. (2000). Reprinted with permission from International Journal for Parasitology.

Figure 2: Avian pox tumor on the eye of Laysan finch. From Warner (1968), The Condor. Reprinted with permission from The Condor. 